\title{
VISIBILIDADE DO TRABALHO PESQUEIRO: REQUALIFICAÇÃO DE ESPAÇO PARA COOPERATIVA DE PESCADORES DE JAGUARÃO/RS
}

VISIBILITY OF FISHERY WORK: REQUIREMENT OF SPACE FOR COOPERATIVE OF FISHERMEN OF JAGUARÃO / RS

\author{
Jeferson Francisco Selbach ${ }^{1}$ Lígia Maria Ávila Chiarelli ${ }^{2}$ \\ Jane Soares Centeno ${ }^{3}$ Olimar Jesus Ferreira Porto ${ }^{4}$
}

\section{RESUMO}

Contribuir com a manutenção do trabalho cooperado é fomentar os princípios de autogestão social, econonomia solidária, reciprocidade e desenvolvimento do fazer comunitário. Os pescadores de Jaguarão (RS) sindicalizados se organizaram em uma Cooperativa para pleitear junto à Prefeitura Municipal a cedência de um galpão para implantar um centro de recebimento de pescados e comercialização da produção. O objetivo da proposta de ação foi contribuir com a visibilidade do trabalho pesqueiro, através de elaboração de proposta de requalificação espacial deste galpão municipal. Pretendeu-se possibilitar ocupação adequada em termos de otimização do espaço. Fez parte da atividade organizar, em colaboração com os futuros usuários, material de campanha de arrecadação junto à comunidade jaguarense, visando aquisição de equipamentos e mobiliário, bem como a reforma pretendida. Foram realizadas: reunião entre a equipe executora e os pescadores para levantamento das demandas de uso do espaço; visita em loco para levantar os principais itens necessários à elaboração de uma proposta de ocupação; elaboração e apresentação da proposta arquitetônica através de pranchas; elaboração do material de campanha. Concluímos que, através de assessoria projetual prestada à Cooperativa, potencializou-se o pleito dos pescadores junto à Prefeitura Municipal para que cedência do galpão, ocorreu a união dos pescadores em torno de um projeto coletivo e a publicização do trabalho pesqueiro para a comunidade jaguarense. A proposta extensionista

\footnotetext{
1 Doutor em História, Mestre em Planejamento Urbano e Regional, Licenciado em Ciências Sociais. Professor na Universidade Federal do Pampa, Campus Jaguarão. E-mail: jfselbach@ hotmail.com. ${ }^{2}$ Doutora em História, Mestre em Desenvolvimento Social e em Engenharia Civil, Bacharel em Arquitetura e Urbanismo. Professora na Universidade Federal de Pelotas, Faculdade de Arquitetura e Urbanismo. E-mail: biloca.ufpel@gmail.com. ${ }^{3}$ Bacharelanda em Arquitetura e Urbanismo na Universidade Federal de Pelotas, Faculdade de Arquitetura e Urbanismo. E-mail: janescenteno@gmail.com. ${ }^{4}$ Bacharelando em Produção e Política Cultural na Universidade Federal do Pampa, Campus Jaguarão. E-mail: olimarpescador@hotmail.com.
} 
foi avaliada como pertinente, pois alcançou seus objetivos de realizar o projeto arquitetônico e o material de campanha, bem como em relação à aprendizagem, ao envolver a equipe executora com uma comunidade de baixa renda e contribuir em termos de políticas públicas.

Palavra-chave: Cooperativas de pescadores. Assessoria projetual. Ocupação especial. Jaguarão.

\begin{abstract}
Contributing to the maintenance of cooperative work is to promote the principles of social self-management, solidarity economy, reciprocity and the development of community doing. The unionized fishermen of Jaguarão (RS) organized in a Cooperative to plead with the City Hall to give a shed to establish a center for receiving fish and commercialization of production. The objective of the action proposal was to contribute to the visibility of fishing work, through the elaboration of a proposal for the spatial requalification of this municipal shed. It was intended to enable adequate occupancy in terms of space optimization. It was part of the activity to organize, in collaboration with future users, collection campaign material with the community of Jaguar, aiming to purchase equipment and furniture, as well as the intended reform. The following were carried out: a meeting between the executing team and the fishermen to survey the demands of space use; on-site visit to raise the main items needed to prepare an occupation proposal; elaboration and presentation of the architectural proposal through planks; preparation of campaign material. We conclude that, through the design assistance provided to the Cooperative, the fishermen's litigation with the City Hall was strengthened so that the shedding of the shed occurred, bringing together the fishermen around a collective project and publicizing the fishing work for the Jaguar community. The extensionist proposal was evaluated as pertinent, as it achieved its objectives of carrying out the architectural project and the campaign material, as well as in relation to learning, by involving the executing team with a low income community and contributing in terms of public policies.
\end{abstract}

Keywords: Cooperatives of fishermen. Projective advice. Space occupation. Jaguarão. 


\section{INTRODUÇÃO}

Desde a decada de 70, com a Conferência das Nações Unidas (ONU) sobre Meio Ambiente, muito se tem discutido e buscado formas de sustentabilidade no mundo, por um desenvolvimento econômico e social que priorize a natureza e respeiteosimpactos gerados pelas diversas atividades econômicas, principalmente as que impactam o meio ambiente. Ribeiro Neto e Oliveira (2013) destacam que o viés sustentabilidade engloba fatores econômicos, sociais, políticos, ideológicos, culturais, históricos, além do meio ambiente, e que os recursos naturais precisam ser utilizados sem prejuízo das gerações presentes e futuras.

A pesca é uma das atividades que vem sendo objeto de preocupação por parte dos que dela dependem, das políticas públicas e da comunidade em geral, devido às práticas predatórias que engendram o aumento do consumo de pescado no mercado e, consequentemente, seu valor. No municipio de Jaguarão existem cinquenta e oito pescadores cadastrados no Sindicato dos Pescadores (SINDIPESCA). Os pescadores sindicalizados pleiteam junto à Prefeitura Municipal pela cedência de galpão localizado ao lado da sede do Sindicato, com aproximadamente $640 \mathrm{~m}^{2}$, para nele implantar um centro de recebimento de pescados e comercialização da produção. Para poderem receber em comodato o galpão, estão organizando uma cooperativa.

A proposta de trabalho extensionista com o SINDIPESCA buscou contribuir com a visibilidade do trabalho pesqueiro no município, através de assessoria projetual para ocupação espacial de galpão municipal. Procurou-se propor adequação de espaço, através elaboração detalhada de proposta arquitetônica, com maquetes eletrônicas, plantas baixas, orçamentos detalhados, entre outros; e organizar material de campanha para ser utilizado junto à comunidade jaguarense para arrecadação de apoio financeiro visando a aquisição de equipamentos e mobiliário. A ação justifica-se no contexto do fomento à preservação do trabalho cooperado, entendido como manifestação da cultura local, em âmbito da economia solidária.

A proposta de extensão teve início com o levantamento das demandas de uso do espaço no galpão municipal por parte do SINDIPESCA. Neste primeiro encontro foi realizada reunião com a equipe executora e com membros do sindicato, onde foram pontuadas as principais expectativas em relação à ocupação do galpão. No mesmo dia, a equipe executora realizou visita in loco ao galpão 
municipal, para levantar os principais itens necessários à elaboração de uma proposta de ocupação, tais como medição do espaço, características morfológicas, orientação solar, tipo de construção.

Com base nestes aspectos técnicos, a equipe executora procedeu com a elaboração de proposta para apresentar ao SINDIPESCA, através de maquetes eletrônicas e planta baixa situacional e propositiva. Após a reunião de apresentação da proposta, a equipe executora procedeu com a elaboração de material para campanha publicitária objetivando arrecadação de apoio financeiro para aquisição de equipamentos e mobiliário contidos no projeto de ocupação do galpão municipal. Cópia eletrônica do material publicitário foi encaminhada ao sindicato. A atividade de extensão finalizou com reunião de avaliação dos resultados obtidos na assessoria.

\section{SUSTENTABILIDADE A PARTIR DA PESCA ARTESANAL}

Atividades pesqueiras são encontradas em praticamente todos os litorais das mais diversas regiões do planeta e no Brasil não poderia ser diferente, devido à longa extensão de costa marítima (Amazônia Azul) e à diversidade de rios e lagoas em seu território. $O$ que faz da atividade pesqueira algo importante, devido ao seu aspecto econômico e sua função social. A pesca está de acordo com a tradição ligada à comunidades costeiras, as quais, devida sua baixa especialização e elevados níveis de pobreza, fazem dela a principal fonte de renda, "portanto uma ocupação importante no contexto socioeconômico" (RODRIGUES; GIUDICE, 2011).

De acordo com a Organização das Nações Unidas para Alimentação e Agricultura (FAO), em 2000 o Brasil ocupou a $24^{a}$ posição no ranking internacional como produtor de pescado, fato que torna o país uma potência em desenvolvimento neste setor. Além disso, o país conta com uma vantagem natural ao desenvolvimento da atividade, devido a sua ampla costa e suas condições climáticas, bem como a sua grande variedade de espécies de pescado disponível.

A pesca artesanal é a atividade comercial realizada através de trabalho manual do pescador. Se diferencia da industrial de acordo com o estado ou região, sendo definida com base nos "equipamentos que são utilizados, tipo de em- 
barcação, e na quantidade de pescado obtido" (LOPES, 2004). Pode ser classificada em dois tipos: pesca artesanal de subsistência e pesca artesanal comercial ou de pequena escala. Segundo o autor, a pesca artesanal de subsistência tem como principal finalidade "a obtenção de alimentos para consumo próprio", enquanto a pesca artesanal comercial ou de pequena escala "combina a obtenção de alimento para consumo próprio com a finalidade comercial.

Dados publicados no Diagnostico do setor pesqueiro do Rio Grande do Sul (2003), pela Superintendencia de Desenvolvimento da Pesca (SUDEPE), colocam o Rio Grande do Sul (RS) como o Estado com um dos maiores litorais do país, com $622 \mathrm{~km}$ de extensão, o que representa $8,39 \%$ do total brasileiro. O RS possui considerável bacia hidrográfica, que pode ser dividida em duas grandes áreas: a do rio Uruguai e a Atlântica, que engloba o sistema dos rios Vacacaí-Jacuí e o sistema de lagoas Mirim, Mangueira e dos Patos. A pesca artesanal no Estado é realizada em pequenas embarcações ou até mesmo nas margens das lagoas ou rios, sobre pequenos cardumes e muitas vezes, utilizada como atividade complementar de subsistência das famílias.

O município de Jaguarão é banhado pelo rio Jaguarão que deságua na Lagoa Mirim. Tanto o rio quanto a lagoa são os principais locais de trabalho dos pescadores da região. $\mathrm{O}$ maior peso da economia municipal está na agricultura e na pecuária. Porém, a pesca vem adquirido importante papel ao longo dos últimos anos, principalmente no entorno da Lagoa Mirim. Os pescadores sindicalizados se utilizam de embarcações de madeira entre cinco e nove metros de comprimento e motores com potência de $5 \mathrm{hp} \mathrm{a} 36 \mathrm{hp}$. Além destas embarcações, costumam usar pequenos botes de até quatro metros, conhecidos como "caícos", que acompanham os maiores e são usados para pesca com redes. Poucos pescadores artesanais ainda confeccionam suas próprias redes, sendo que a maioria compra redes já prontas ou semi-prontas nas lojas revendedoras de materiais especializado (PORTO, 2016).

De acordo com Fernandes et al. (2006), a principal preocupação dos pescadores que pescam artesanalmente na Lagoa Mirim é relacionada com a grande diminuição de pescado e "da possibilidade de inviabilização da pesca artesanal". Uma das possiveis causas desse problema seria a construção de uma eclusa em 1977, no canal São Gonçalo, o que causou algumas mudanças no habitat de algumas espécies, impedindo o ingresso de tainhas, bagres, linguados e corvinas na Lagoa Mirim. Outro motivo seria a expansão das lavouras de arroz e soja que, 
ainda segundo o autor, "drenam as várzeas onde ocorreriam a área de criação das espécies". Contudo, os maiores problemas seriam a falta de fiscalização e de regulamentação da pesca na lagoa em território uruguaio e a baixa remuneração pelo pescado, fatores que prejudicam a atividade no municipio.

Em decorrência deste contexto socioeconômico da comunidade pesqueira jaguarense é que surgiu a idéia de formar uma cooperativa. Contribuir com a manutenção do trabalho cooperado é, neste sentido, fomentar os princípios de autogestão social, economia solidária, reciprocidade e desenvolvimento do fazer comunitário, possibilitando unir indivíduos muitas vezes excluídos do mercado de trabalho formal, que buscam adquirir maior autonomia nos saberes do trabalho (SENNETT, 2009; KELLER, 2014). O trabalho cooperado pode ser considerado elemento formador de identidade cultural de grupos sociais, possibilitando o desenvolvimento econômico local e, portanto, algo que possui valor material e imaterial (CANCLINI, 1995).

\section{CONTRIBUIÇÃO PARA A VISIBILIDADE DO TRABALHO PESQUEIRO}

No primeiro contato com o SINDIPESCA, foi possível levantar as principais demandas do espaço pleiteado junto à Prefeitura Municipal. A proposta é que o espaço seja destinado para o recebimento de pescados, com uma sala para filetagem, e comercialização da produção, com sala específica e adequada. Foram listados os equipamentos necessários para ambas atividades que seriam desenvolvidas, tais como bancadas, pias, refrigeradores, freezers, mesas e cadeiras, bem como algumas especificações de reforma, como revestimento cerâmico nas paredes.

Em seguida a esta reunião inicial, foi realizada visita in loco. O galpão está localizado na esquina da rua Atahuaira Gonçalves Dias com avenida 20 de Setembro, atrás do Presídio Estadual e ao lado da Ponte Internacional Barão de Mauá, sobre o rio que faz fronteira entre Brasil e Uruguai (Fig. 1). 
Figura 1 - Imagem de satélite da zona urbana de Jaguarão, com destaque para o galpão municipal.

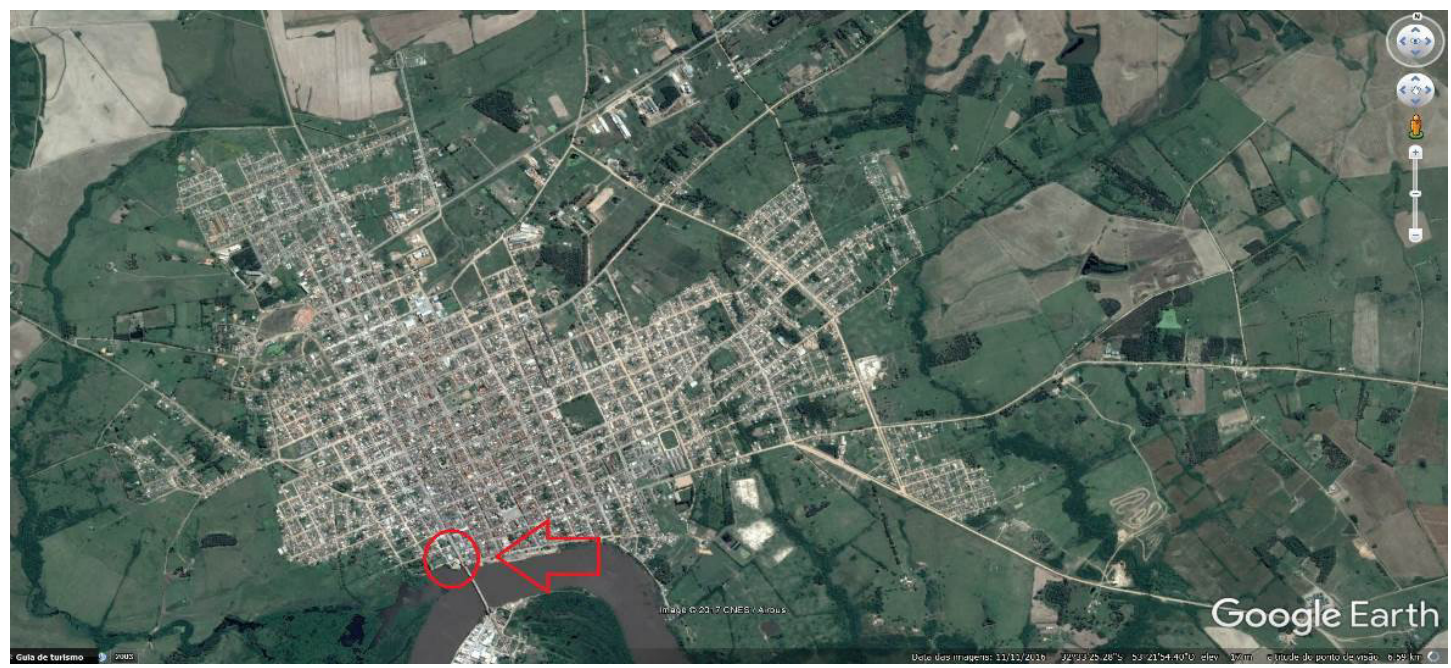

Fonte: Imagem do Google Earth, acessada em 11/07/2017.

O galpão mede $32 \mathrm{mt} \times 20 \mathrm{mt}$, totalizando $640 \mathrm{~m}^{2}$ de área coberta, sustentado por 14 pilastras de ferro, 7 de cada lado. Está assentado numa base elevada de concreto (Fig. 2). A área fechada de alvenaria mede $13 \mathrm{mt} \times 3,15 \mathrm{mt}$ e tem 2 salas $\left(7 \mathrm{~m}^{2}\right.$ e $\left.11,5 \mathrm{~m}^{2}\right)$ e 2 banheiros coletivos com pias e 3 cabines com vasos sanitários cada. As aberturas são protegidas por grades de ferro. 0 teto é de laje de concreto. Foi construído para ser um centro de comércio informal, popularmente chamado de camelódromo por abrigar barracas de comercialização de produtos importados. Nunca chegou a ser utilizado para isto. Atualmente, o galpão está em desuso e abriga eventualmente moradores de rua, serve de estacionamento informal e é objeto de depredação. Constatou-se lixo espalhado no local (Fig. 3). 
Figuras 2 e 3 - Fachada sul do galpão municipal e construção em alvenaria.
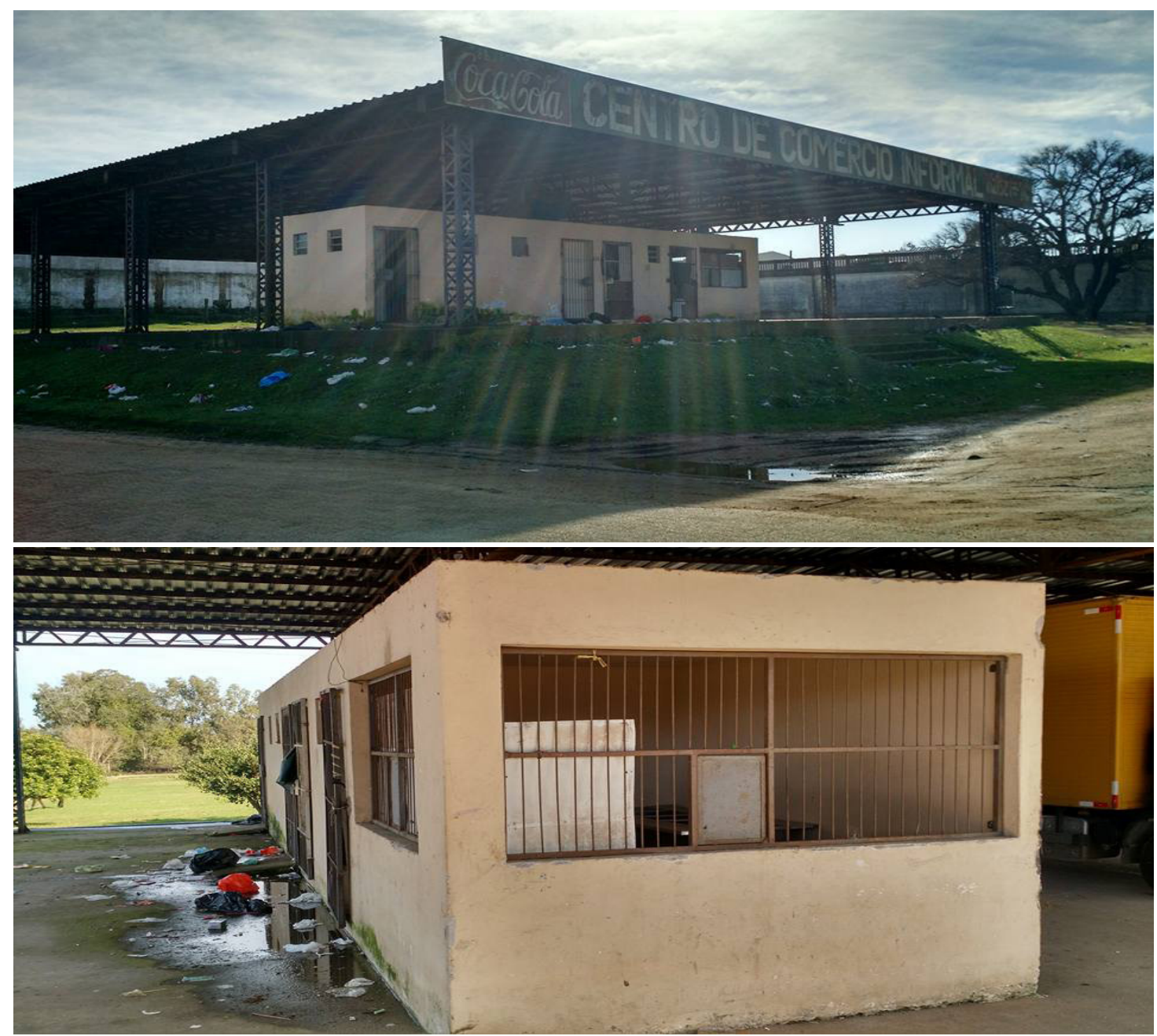

Fonte: Imagens próprias dos autores.

A elaboração da proposta deu-se em três etapas: planta baixa situacional e propositiva, maquetes eletrônicas e renderização e material de campanha publicitária. A planta baixa situacional foi feita com as medidas encontradas na visita in loco. A partir dela foram estabelecidas as áreas que seriam destinadas a cada atividade: área amarela para o espaço de convivência; área verde para o espaço de comercialização e circulação, com acesso aos banheiros masculino e feminino; e área rosa para a parte de alvenaria, com os dois banheiros e as salas de recebimento de pescados e de comercialização da produção (Fig. 4). 
Figura 4 - Planta baixa do galpão municipal com as definições de ocupação.

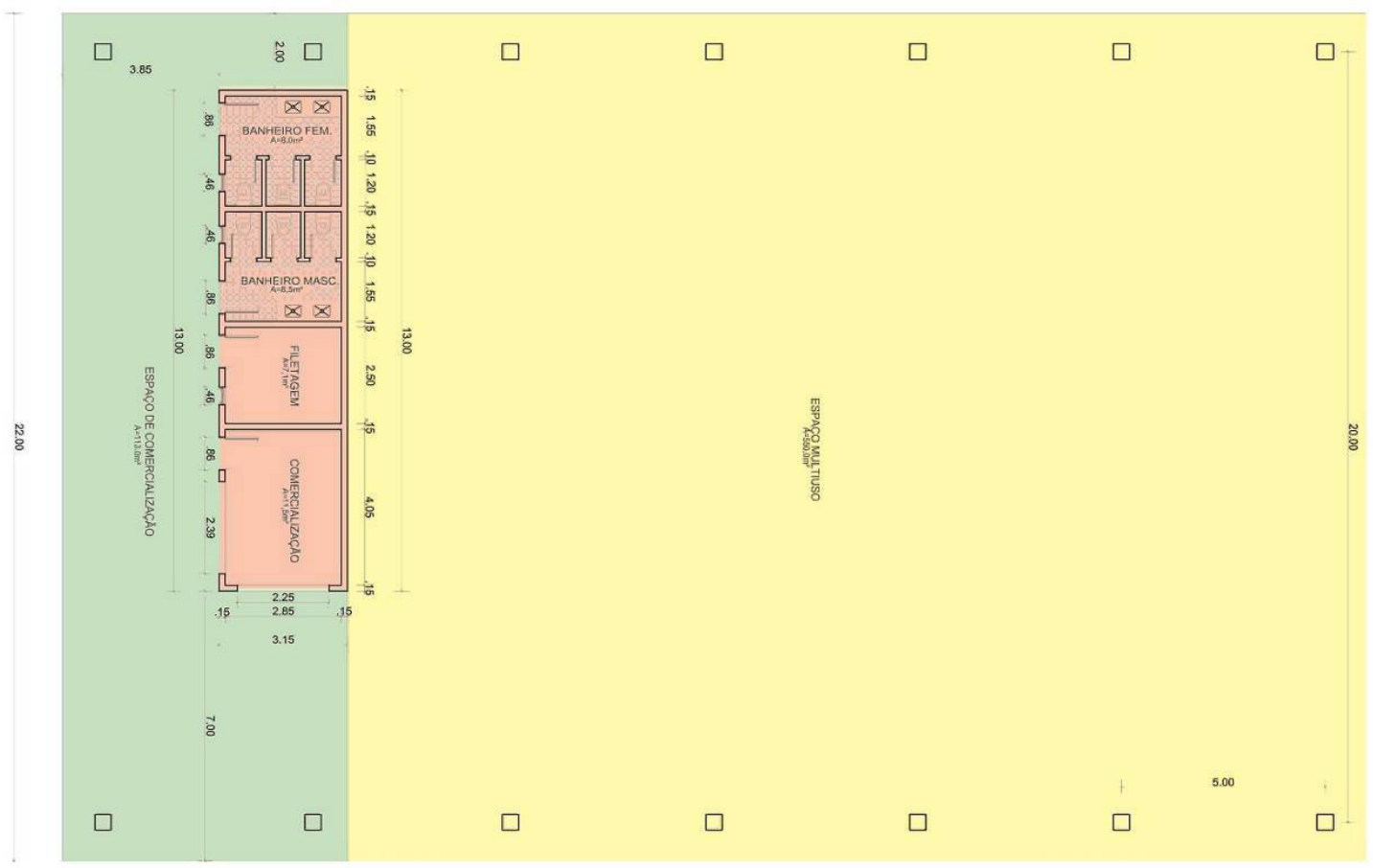

Fonte: Desenho realizado pelos autores.

A área rosa é a parte de alvenaria. Pela proposta, as duas salas da parte fechada do galpão serão ocupadas para recebimento de pescados e comercialização da produção.

A primeira sala a ser ocupada tem $7 \mathrm{~m}^{2}$, com medidas de $2,5 \mathrm{mt} \times 2,85 \mathrm{mt}$. Deverá ser equipada com bancadas de pedra granito ou alumínio e terá de contar com no mínimo 1 pia para lavagem dos pescados. O piso e as paredes deverão ser revestidos com azulejo cerâmico ou porcelanato até o teto, preferencialmente nas cores claras. A iluminação deverá ser clara, com pontos de luz focando para duas ou três direções, de modo a facilitar o trabalho a ser desenvolvido. A rede elétrica deverá contar com dois pontos de energia (tomadas) em cada parede. Para manter refrigerados os pescados, a sala deverá ter um freezer horizontal, com capacidade mínima de quinhentos litros e abertura em duas tampas. 
Para demonstrar a proposta desta sala foi feita maquete eletrônica através do programa Sketchup (Fig. 5).

Figura 5 - Sala destinada a filetagem.

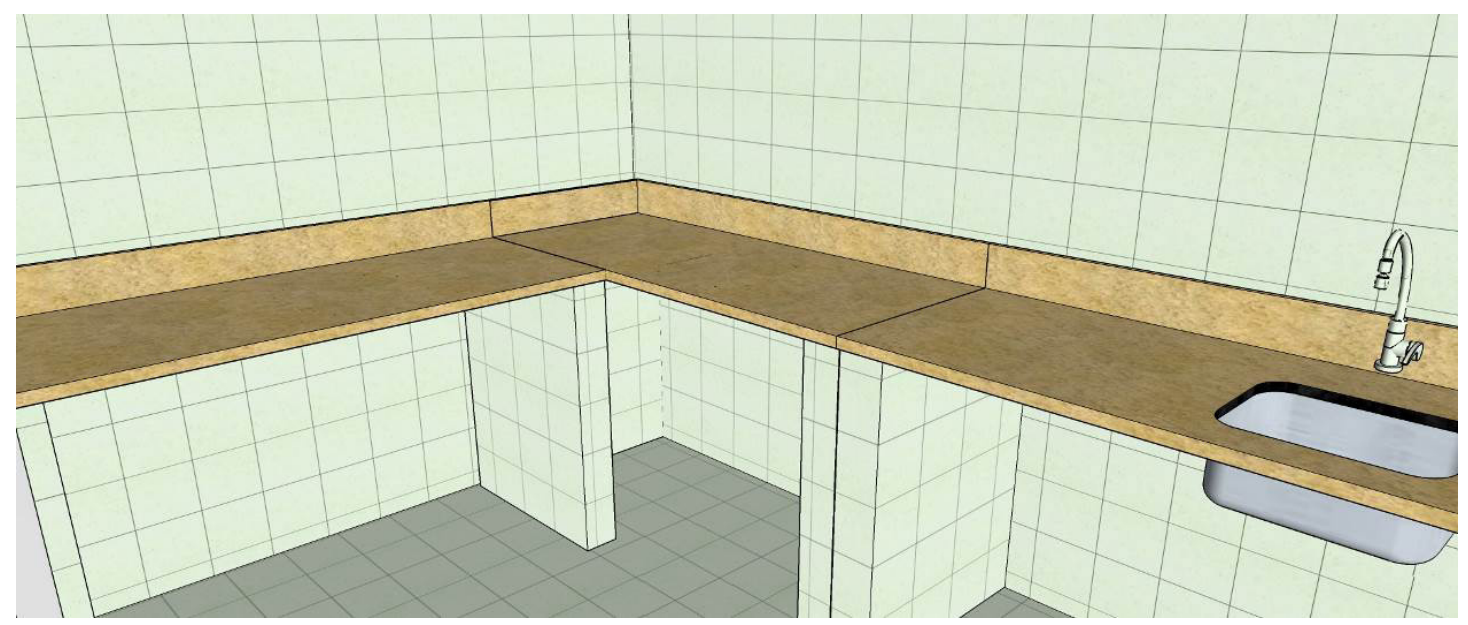

Fonte: Modelagem realizada pelos autores.

A segunda sala a ser ocupada tem $11,5 \mathrm{~m}^{2}$, com medidas de $4,05 \mathrm{mt} \times 2,85 \mathrm{mt}$, e será destinada para a comercialização da produção de pescados. Para tanto, deverá ser equipada com bancada de pedra granito ou alumínio e balcão de MDF ou MDP na parte inferior, para possibilitar a guarda de equipamentos ou embalagens. Também deverá ter balcão com pia para lavagem dos pescados e mesa com cadeira para servir de espaço para a movimentação financeira. 0 piso e as paredes deverão igualmente ser revestidos com azulejo cerâmico ou porcelanato até o teto, preferencialmente nas cores claras. A iluminação também deverá ser clara, com pontos de luz focando para duas ou três direções, e a rede elétrica deverá contar com pontos de energia (tomadas) em cada parede. Para manter refrigerados os pescados, a sala deverá ter um freezer horizontal, com capacidade mínima de quinhentos litros e abertura em duas tampas, e um ou dois freezers verticais, com cento e quarenta litros cada. Esta sala possui duas aberturas de 2,25 mt de largura x 1,20 mt de altura. Para melhorar a segurança, propõe-se a instalação de folhas de fechamento (madeira ou alumínio) em forma de tesoura horizontal, que ao abrirem servirão de balcão para os clientes (Fig. 6). Além destas duas salas, a parte de alvenaria (marcada em rosa) traz ainda os banheiros femino e masculino (Fig. 7). 
Figuras 6 e 7 - Sala destinada à comercialização da produção e banheiro.

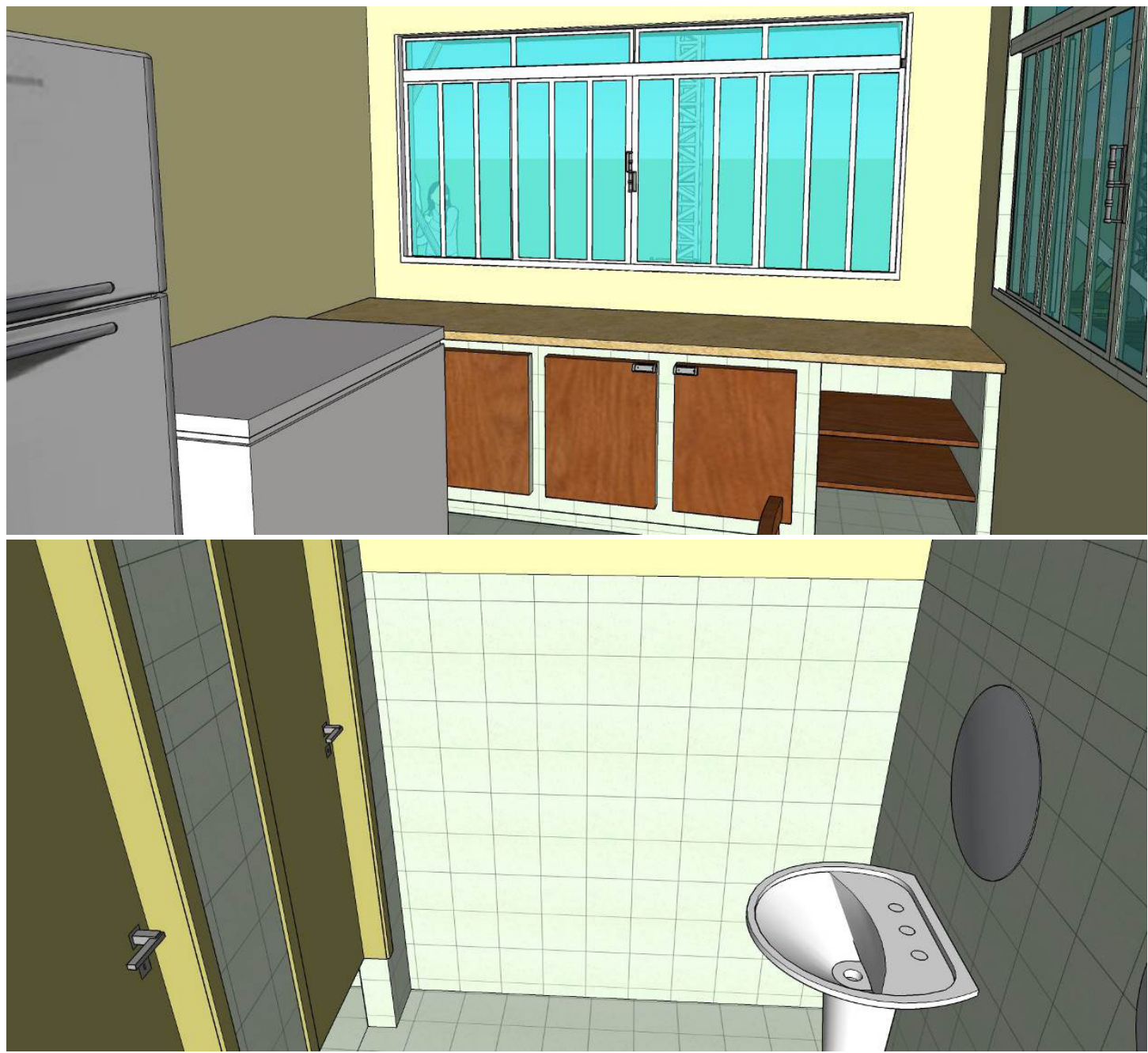

Fonte: Modelagem realizada pelos autores.

Na parteaberta do galpão, foram delimitados doisespaços. Naárea amarela, em torno de $550 \mathrm{~m}^{2}$, para a convivência ou espaço multiuso, com o desenvolvimento de outras atividades econômicas, como feiras de produtores rurais orgânicos, comercialização de mudas e folhagens, pequenas barracas para venda de produtos comestíveis (cachorro-quente, pipoca, churros), livros novos e usados (sebo) ou briques de móveis, utensílios e antiguidades. O espaço também poderá ser utilizado para atividades culturais e de recreação, para shows e performances artísticas, 
brinquedoteca e espaço de leitura (Fig. 8). A área verde tem aproximadamente $113 \mathrm{~m}^{2}$ e deverá ser destinada à circulação dos clientes, mas também poderão ser postas mesas e cadeiras, para tornar a estada dos clientes mais agradável (Fig. 9).

Figuras 8 e 9 - Espaço multiuso e espaço de circulação.
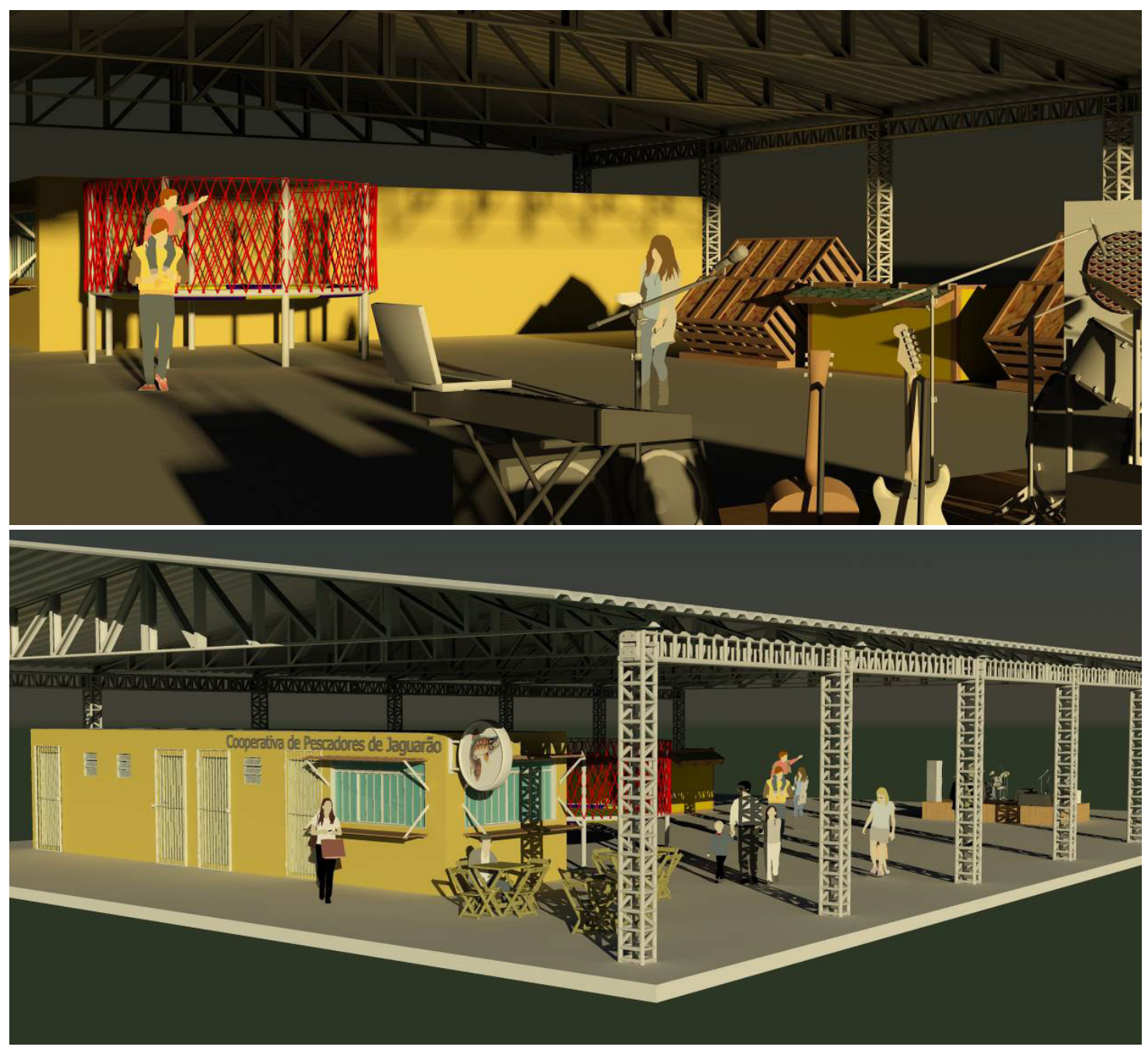

Modelagem e renderização realizada pelos autores. 
Para o material de campanha publicitária foi elaborado um cartaz em A3, para ser impresso em gráfica e distribuído em locais estratégicos, como padarias, postos de gasolina, lojas de vestuário, de materiais de construção, de eletrodomésticos e farmácias (Fig. 10). A proposta foi apresentada em reunião realizada em na sede do SINDIPESCA. Contou com a participação da equipe executora e de seis pescadores sindicalizados.

A apresentação foi realizada a partir de seis pranchas elaboradas em A3, impressas coloridas. Na primeira prancha foi inserida imagem renderizada da fachada sul do galpão municipal e texto explicativo introdutório sobre a cooperativa e o projeto de extensão (Fig. 10). Na segunda prancha foi inserida imagem renderizada da área de circulação com as mesas e texto explicativo sobre como foram realizadas as etapas do projeto (Fig. 11). Na terceira prancha foi inserida imagem interna da maquete eletrônica da sala de filetagem e texto explicativo sobre como deveria ser reformada e adaptada a sala para receber os pescados (Fig. 12). Na quarta prancha foi inserida imagem interna da maquete eletrônica da sala de comercialização da produção e texto explicativo sobre como deveria ser reformada e adaptada a sala para as atividades (Fig. 13). Na quinta prancha foi inserida imagem renderizada da parte do espaço multiuso, com palco para shows, barracas de comercialização de verduras e equipamentos de recreação infantil (cama-elástica) e texto explicativo de como poderia ser ocupado este espaço (Fig. 14). Na sexta e última prancha foi inserida a planta baixa com detalhamento do espaço (Fig. 15).

Figuras 10 a 15 - Pranchas apresentadas aos pescadores.
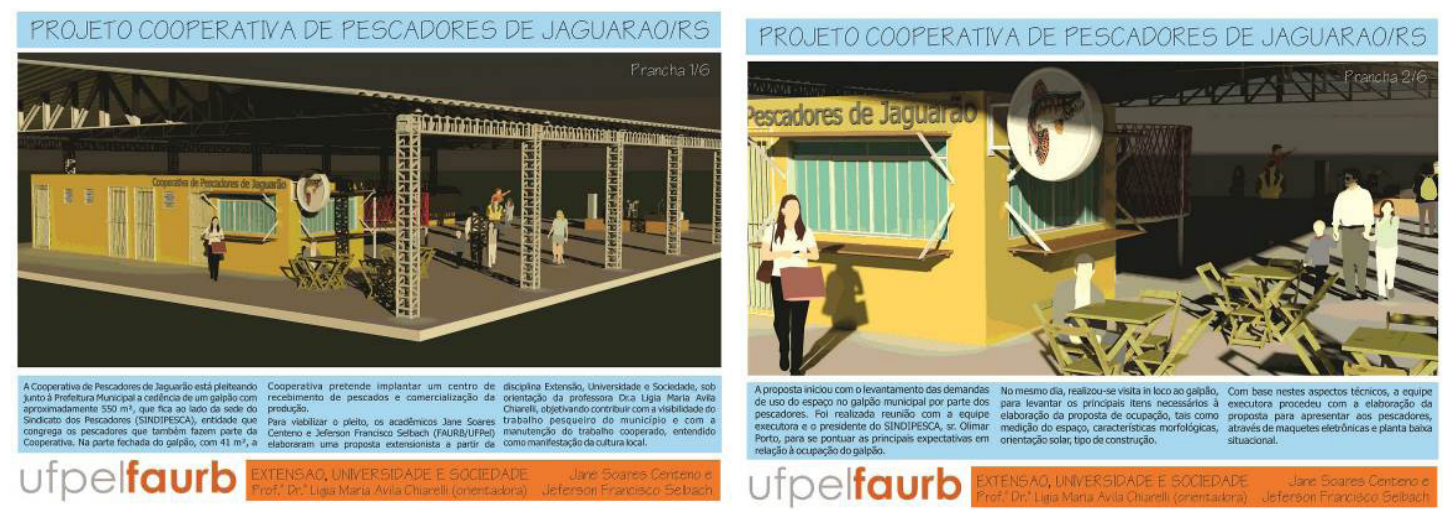


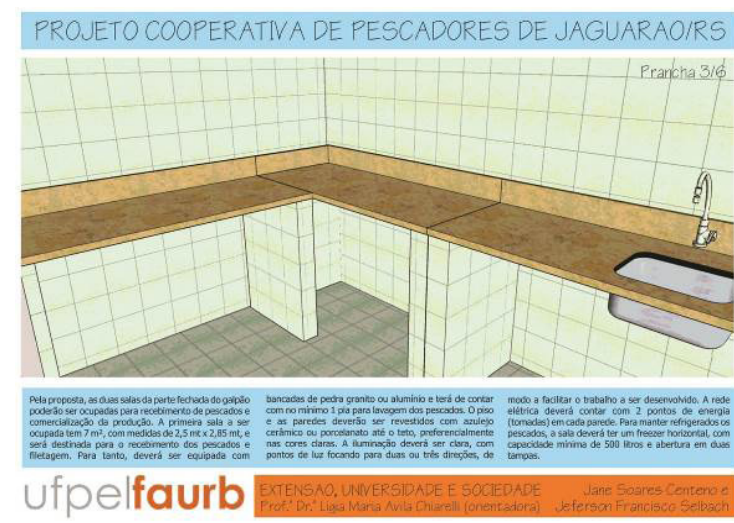

PROJETO COOPERATIVA DE PESCADORES DE JAGUARAOIRS

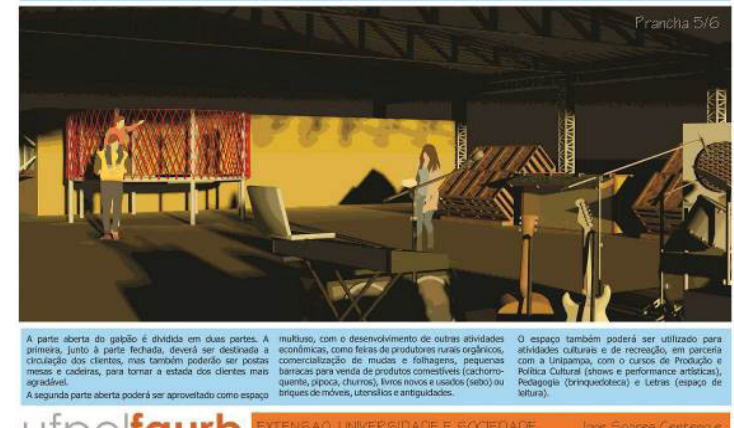

ufpelfaurb

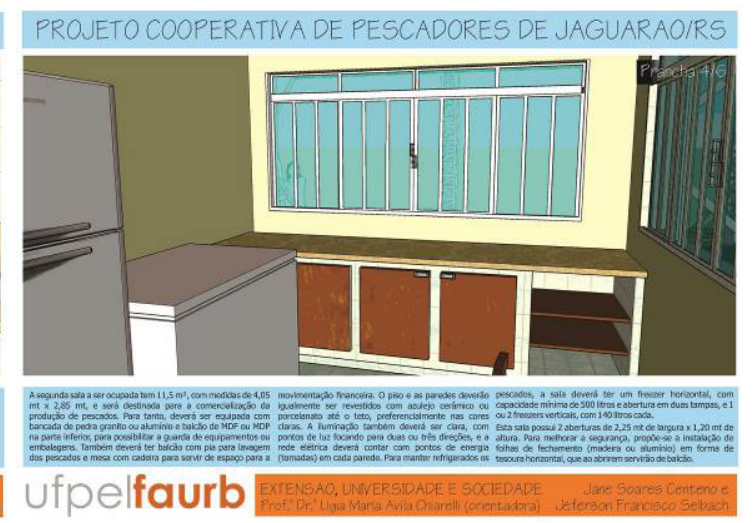

PROJETO COOPERATIVA DE PESCADORES DE JAGUARAOIRS

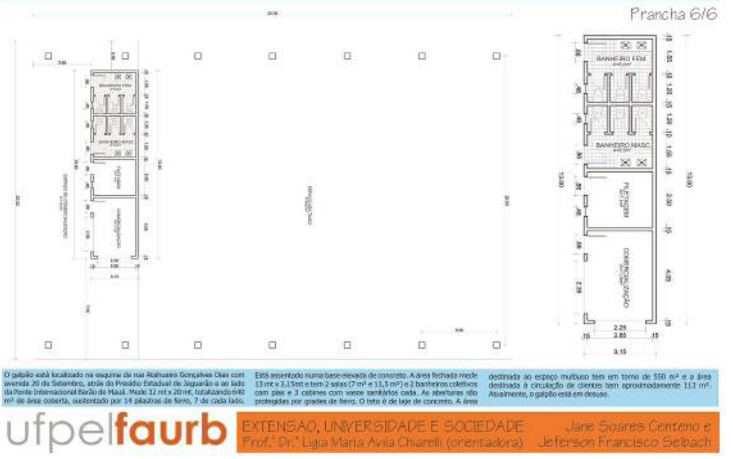

Fonte: Imagens próprias dos autores.

O recebimento da proposta por parte dos pescadores foi considerada bastante positiva. Disseram ter gostado muito da divisão espacial proposta, que o fato de trazer um espaço multiuso, para atividades de outros comércios como feiras de produtos orgânicos ou mesmo atividades culturais, poderia agregar público ao comércio de pescados, fazendo aumentar a renda dos cooperados. Esta questão poderia impulsionar o hábito da população local consumir mais pescados da própria região que, apesar de ser banhada pelo rio Jaguarão, ainda consideram baixo o consumo per capita.

$\mathrm{Na}$ adequação das salas de filetagem fizeram algumas ponderações, como a necessidade das bancadas serem de aço inox e não de pedra granito ou alumínio, isso por recomendação dos próprios órgãos de controle e vigilância sanitária. Solicitaram que a equipe executora apresentasse uma perspectiva orçamentária dos custos para a reforma proposta, o que ficou acertado que seria feito futuramente. 
Segundo relatos pelos próprios presentes, nunca haviam tido contato com um trabalho apresentado de maneira tão detalhada, "parecendo real" segundo afirmaram. Também ressaltaram que o cartaz de divulgação ficou adequado para captar recursos junto à população visando as despesas com a reforma. Este detalhamento apresentado vai ser, segundo os presentes, importante para convencer a Prefeitura Municipal a ceder o galpão para a cooperativa. Isto porque ao apresentar uma proposta bem elaborada, acreditam que conseguirão o apoio necessário do Poder Público. Também acreditam que o detalhamento possibilitará angariar apoio e futuramente recursos junto à comunidade para a ocupação do galpão municipal.

Solicitaram, por fim, que fosse realizada nova reunião com a presença da equipe executora para apresentação da proposta aos demais pescadores filiados ao SINDIPESCA. Isto porque alegaram que nesta primeira reunião de apresentação da proposta o número de participantes foi baixo frente ao número de filiados.

\section{CONCLUSÕES}

Através de assessoria projetual prestada à cooperativa foi possível contribuir com a visibilidade do trabalho pesqueiro no município de Jaguarão/ RS da seguinte forma: se potencializou o pleito dos pescadores junto à Prefeitura Municipal para que ceda o galpão; se uniu os pescadores em torno de um projeto coletivo; se possibilitou mostrar para a comunidade jaguarense o trabalho dos pescadores; se trouxe para âmbito acadêmico o trabalho desenvolvido pelos pescadores.

A avaliação pelo público-alvo da ação extensionista foi considerada adequada, uma vez que se deu a aprovação da proposta de ocupação espacial do galpão municipal pleiteado pela cooperativa, bem como do material de divulgação para arrecadação de apoio financeiro para aquisição de equipamentos e mobiliário.

Em termos de aprendizagem considera-se positivo o desenvolvimento do trabalho extensionista, visto que a equipe executora pôde ter contato efetivo com os pescadores, algo que enriquece as experiências acadêmicas, por ser comunidade de baixa renda. A partir desta experiência reforça-se a concepção de que a Arquitetura pode e deve contribuir com políticas públicas de inclusão social. 


\section{REFERÊNCIAS}

CANCLINI, N. G. As culturas populares no capitalismo. São Paulo: Brasiliense, 1995.

FERNANDES, L. A. et al. Pesca artesanal na Lagoa Mirim, RS. Conflitos de interesses e ameaças à sustentabilidade do ecossistema costeiro. In: ENCONTRO DA SOCIEDADE BRASILEIRA DE ECONOMIA ECOLÓGICA, 7., 2007, Fortaleza. Anais do... Fortaleza, 2007.

KELLER, P. O artesão e a economia do artesanato na sociedade contemporânea. Maranhão, Revista de Ciências Sociais, Maranhão, n. 41, 2014.

LOPES, F. C. 0 conflito entre a exploração off $\neg$ shore de petróleo e a atividade pesqueira artesanal. 2004.57f. Dissertação (Mestrado em Economia)-Universidade Estadual do Rio de Janeiro, Instituto de Economia, Rio de Janeiro, 2004.

ORGANIZACIÓN DE LAS NACIONES UNIDAS PARA LA ALIMENTACIÓN, AGRICULTURA. El estado mundial de la pesca y la acuicultura. Roma: FAO, 2000.

PORTO, O. J. F. Pesca profissional artesanal como forma de trabalho e geração de renda familiar de modo sustentável. Monografia (Produção e Política Cultura). Jaguarão: Unipampa, 2016.

RIBEIRO NETO, R. H.; OLIVEIRA, C. C. L. Análise de sustentabilidade da atividade pesqueira da população ribeirinha do município de Macapá. (Monografia). Macapá: Universidade Federal do Amapá. Departamento de Meio Ambiente e Desenvolvimento, 2013.

RODRIGUES, J. A.; GIUDICE, D. S. a pesca marítima artesanal como principal atividade socioeconômica: o caso de Conceição de Vera Cruz, BA. Cadernos do Logepa, v. 6, n. 2, p. 115-139, jul./dez. 2011.

SENNETT, R. A corrosão do caráter: as consequências pessoais do trabalho no novo capitalismo. 14. ed. Rio de Janeiro: Record, 2009.

SUDEPE. Diagnóstico do setor pesqueiro do Rio Grande do Sul. Maio de 1988 revisado em janeiro de 2003. Disponivel em: <www.icmbio.gov.br/ceperg/images/ stories/publicacoes/titulo10.pdf >. Acesso em: 16 dez. 2016.

Data de recebimento: 10 de outubro de 2017.

Data de aceite para publicação: 19 de dezembro de 2017. 